\title{
Liposomes as a Tool to Study Lipid Peroxidation
}

\author{
Biljana Kaurinovic and Mira Popovic
}

Additional information is available at the end of the chapter

http://dx.doi.org/10.5772/46020

\section{Introduction}

Lipid peroxidation is used as a marker of cellular oxidative stress and contributes to the oxidative damage that occurs as a result of xenobiotics metabolism, inflammatory processes, ischemia, reperfusion injuries and chronic diseases such as atherosclerosis and cancer [1,2].

Cell membrane lipids (phospholipids, glycolipids and cholesterol) are the most common substrates of oxidative attack. Once initiated reaction autocatalytic continues, it has progradient flow, and the ultimate consequence is the structural-functional changes of the substrate. Lipid peroxidation is one of the best studied processes of cell damage under conditions of oxidative stress [3-5]. In 1960s Hochstein et al. [6] found that the initiation of lipid peroxidation require the presence of iron ions. From that moment the mechanism of lipid peroxidation process has been studied in many in vitro systems. However, accurate and precise mechanism is still not fully understood. Peroxidation in liposomes is usually studied after adding iron ions ( $\mathrm{Fe}^{2+}$ plus ascorbic acid). Although the mechanism is not fully understood, it is known that redox chemistry of iron plays an important role in the occurrence and the rate of lipid peroxidation. Many studies have shown that the irondependent lipid peroxidation in systems comprised initially of $\mathrm{Fe}^{2+}$ and liposomes requires $\mathrm{Fe}^{2+}$ oxidation. In their research work, Minotti and Aust [7] assumed that the complex is formed between $\mathrm{Fe}^{2+}$ and $\mathrm{Fe}^{3+}$ ions could be initiator of iron-dependet lipid peroxidation. However, the existence of this complex has never been proven. In contrast, Aruoma et al. [8] argue against the participation of a $\mathrm{Fe}^{2+}-\mathrm{Fe}^{3+}-\mathrm{O}_{2}$ complex, or a critical 1:1 ratio of $\mathrm{Fe}^{2+}$ to $\mathrm{Fe}^{3+}$, in the initiation of lipid peroxidation in liposomes. Study of Tang et al. [9] showed that whether adding 100 or $150 \mathrm{mM} \mathrm{Fe}{ }^{2+}$ initially or adding $100 \mathrm{mM} \mathrm{Fe}^{2+}$ initially and then $50 \mathrm{mM}$ $\mathrm{Fe}^{2+}$ later at various times during the latent period in the liposomal system, the concentration of the remaining $\mathrm{Fe}^{2+}$ at the end of the latent period was almost the same every time.

Since lipid peroxidation causes oxidative damage to cell membranes and all other systems that contain lipids, in investigation of total antioxidative activity of plant extracts it is necessary to investigate their effects on lipid peroxidation. However, the impact of various 
natural products (isolated compounds and extracts) on the intensity of lipid peroxidation is studied in a number of substrate (linoleic acid, liposomes, various fatty oils, liver homogenates or hepatocytes isolated from it). Some substrates (liposomes and linolenic acids) are used more frequently than others mainly because of the simpler ways of performing the method. Also, due to the complex composition, examining the process of lipid peroxidation in fatty oils and liver homogenates makes research more difficult.

\section{Liposomes as a model system}

Liposomes are microscopic structure consisting of the one or more lipid bilayer enclosing the same number of water compartments. First, they were produced in Great Britain in 1961 by Alex D. Bangham while he was studying blood clotting. It was discovered that when phospholipids were combined with water they immediately formed a sphere. This is due to the fact that one end of each molecule is water soluble, while the oposite end is water insoluble. Water-soluble medications added to the water were trapped inside the aggregation of the hydrophobic ends; fat-soluble medications were incorporated into phospholipids layer and then - an important delivery system was born! Generally, such a structure formed polar lipids (such as phospholipids) [10]. Liposomes could be characterized as particles, similar to the structure and composition of cell membrane (Figure 1.). They occur in nature and could be artificially prepared [11].

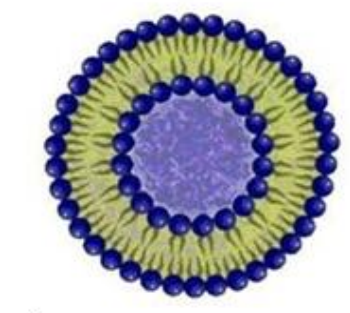

a)
Phospholinid
molecule

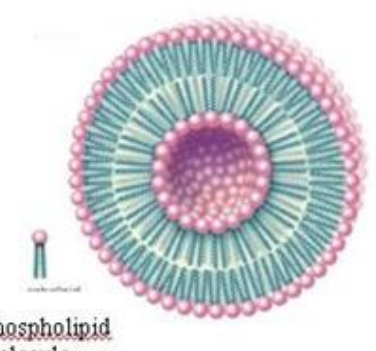

Figure 1. Example of a) empty liposome; b) liposome (2007 Encyclopadeia Britannica, Inc.)

The behaviour of liposomes in physical and biological systems is governed by the factors such as physical size, membrane permeability, percent entrapped solutes, chemical composition (estimation of phospholipids, phospholipids oxidation, and analysis of cholesterol), and quantity and purity of the starting material. Therefore, liposomes are characterized for physical attributes: shape, size, and its distribution; percentage drug capture; entrapped volume; lameliarity; percentage drug release. Based on the structure and size, we distinguish between different types of liposomes: Multilamellar Vesicles (MLV, size

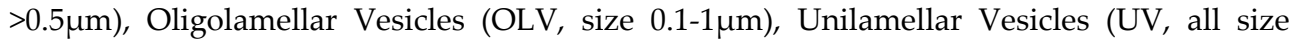
ranges), Multivesicular Vesicle (MVV/MV, size $>1 \mu \mathrm{m}$ ). Unilamellar Vesicles are further divided into Small Unilamellar Vesicles (SUV, size 20-50nm), Medium Unilamellar Vesicles (MUV, size 50-100nm), Large Unilamellar Vesicles (LUV, size $>100 \mathrm{~nm}$ ) and Giant Unilamellar Vesicles (GUV) (Figure 2.). 


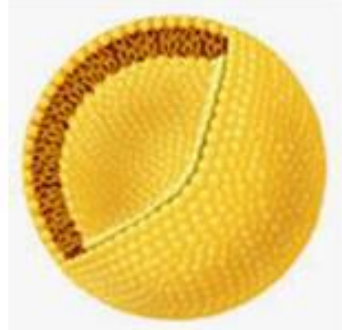

a)

Figure 2. Example of a) unilamellar liposome; b) multilamellar liposome

Based on composition and applications, liposomes are divided into conventional liposomes (CL), fusogenic liposomes, $\mathrm{pH}$ sensitive liposomes, cationic liposomes, long circulatory (stealth) liposomes (LCL) and immuno-liposomes [12]. It is very difficult to measure dirrectly the phospholipid concentration, since dried lipids can often contain considerable quantities of residual solvent. Because of that, the method most widely used is an indirect one in which the phosphate content of the sample is first measured. The phospholipid concentration is measured using two methods - Bartlett and Stewart. In the Bartlett method the phospholipid phosphorous in the sample is first hydrolyzed to inorganic phosphate. This is converted to phospho-molybdic acid by the addition of ammonium molybdate and phospho-molybdic acid is quantitatively reduced to a blue colored compound by aminonaphthyl-sulfonic acid. The intensity of the blue color is measured spectrophotometrically and is compared with the curve of standards to give phosphorous and hence phospholipid content. This method is very sensitive. The problem is that test is easily upset by trace contamination with inorganic phosphate. In the other test, Stewart test, the phospholipid forms a complex with ammonium ferrothiocyanate in organic solution. The advantage of this method is that the presence of inorganic phosphate does not interfere with the test.

Until recently, liposomes are used as inert particles, carries of active principles, mostly for cosmetic purposes [13]. Today liposomes are used as very useful models, reagents and tools in various scientific disciplines, including biophysics (properties of cell membranes and channels), chemistry (catalysis, energy conversion, photosynthesis), biochemistry (the function of membrane proteins) and biology (excretion, cellular functions, transports and signaling, the transfer of genes and their functions). Liposomal formulation of several active molecules are currently in pre-clinical and clinical trials in different fields, with promising results. Two of the key problems in drug therapy (biodistribution throught the body and targeting to specific receptors) can be overcome by using liposomal formulations liposomes protect encapsulated molecules from degradation and can passively target tissues or organs that have a discontinuous endothelium, such as liver, spleen, and bone marrow [14]. Comercial use of liposome was based on their colloidal, chemical and surface and microcapsuled proporties. These products include dosage formes of drugs (anti-cancer and antifugal agents, vaccines), cosmetic formulation (skin care products, shampoos), diagnostic products, a variety of applications in the food chemistry, as well as oral nutrient transport 
(liposomal vitamins, minerals and plants extracts for oral use). Liposome stability is an importrant aspect that must be met to be able to apply. By selecting the optimal value and size, $\mathrm{pH}$ and ionic strenght and the addition of complexing agents, liquid liposomical formulations could be stable for years.

Liposomal models have helped us to better understand the structure and dynamics of natural biomembrane systems. The concepts of structure and function of biomembranes, such as membrane fluidity, phase transition, the movement of lipids and proteins, triggering prosesses that affect metal ions or $\mathrm{pH}$, have been very developed in this way. Modulatind effect of internal molecules (such as cholesterol) and insight into the mechanisms of membrane permeabillity for non-electrolytes and ions, are obtained by testing the model membranes. Liposomes that contains proteins as a components of membrane (reconstructes liposomes) were used in testing lipid-protein interactions in biological membranes, in examining the activities of active components such as membrane ionophores, anesthetics and divalent cations and mechanisms of antybody-antigen interactions [10].

Liposomes are very good models because they show the selectivity of the membrane to ions, osmotic swelling and response of range to agents that speed up or slow down the loss of ions and molecules from the particles in a way that at least, qualitatively mimic their activity in the natural membrane systems. Liposomes have also been successfully applied to "exclude the role" of membranes lipids and other components in biomembranes interact with the physical or chemical agents. Nevertheless, liposomal systems are useful because they allow the manipulation of membrane lipid composition, $\mathrm{pH}$, temperature, content of different compounds in a limited way and provide the ability to determine the individual effect of the investigation product [15].

An example of the advantages of liposome in investigation of lipid peroxidation is that the influence of free radicals can be explored in the absence of chemical systems that produce free radicals, which may affect the test reaction. It is also possible to control the chemical composition of the liposome. This is particularly useful for the determination of lipid peroxidation induced by different systems for the generation of free radicals, and monitoring the overall effect of the combined system, or synergistic effects of combined systems that may arise. In addition to this it is possible to determine the antioxidant activity of tested compounds and determine which system works the best, by simple monitoring of lipid peroxidation. The tests used to determine the power of antioxidants to exert suppression of lipid peroxidation based on an assessment of the strength of oxidation of lipid substrate in the presence or absence of potential antioxidant molecules of plant extracts. There are four different strategies for assessing antioxidant capacity of molecules to the lipid substrate. They include the determination of oxygen consumed, the loss of substrate and formation of primary and secondary oxidation products [16]. The first method for determining the degree of lipid peroxidation, which includes the determination of oxygen consumed, based on following of initiation phase and its extension in the absence of antioxidants. The second method is based on measuring the loss of substrate in systems such as samples of food or biological samples and is very complicated, because they are full 
of potential oxiable substrates that are difficult to identify and characterize. The third method is based on monitoring the formation of primary oxidation products. It is a method that is well adapted to study such complex model systems and often involves the spectrophotometric determination of hydroperoxide, the dominant primary products of lipid peroxidation. Monitoring of secondary products of oxidation is the most commonly used method for the study of lipid model systems and lipid isolated from their natural environment. Both the in vitro and in vivo conditions are very often used TBA (thiobarbituric acid) test for detection of MDA (malondialdehyde), a secondary product of oxidation. This test is based on the reaction between TBA and MDA, which produces red chromophore with maximum of absorbance at $532 \mathrm{~nm}$. This reaction is widely used and is performed by means of determination of many oxiable substrates (free fatty acids, LDL, body fluids). However, this method has some drawbacks. One is that the MDA is formed from free fatty acids which contain at least three double bonds. The next disadvantage is that the TBA is not specific for MDA because it can react with other aldehydes, such as occurs brown color that comes from the reactions of decomposition of sugar, amino acids, proteins and nucleic acids. Finally, MDA is not generated during the oxidation of many lipids and is often less important secondary oxidation product, and therefore not representative enough for the individual measurements. However, the TBA test was held for examination of lipid peroxidation, due to the simplicity of the method.

Despite all these advantage, liposomal systems remain different from the natural cellular systems. For this reason, regardless of the results obtained by testing the liposomes, they could not be reproduced on the natural membrane system, but they can provide useful information.

Therefore, the liposomes are still mostly used as a model system of biological membrane for testing the LP, especially when testing extracts and essential oils from plants on the intensity of LP. These studies are important because free radical oxidation of lipid components of food is a major strategic problem of food producers. The degree of oxidation of fatty acids and their esters in foods depends on the chemical structure of fatty acids, food processing technology, the temperature at which food is stored or prepared for eating and the presence of antioxidants. Synthetic antioxidants are widely used in many foods to retard undesirable changes as a result of oxidation. Chemicals, like tert-butyl-4-hydroxyanisole (BHA) and tertbutyl hydroxytoluene (BHT), can be used as antimicrobial and antioxidants agents. However, the use of some of these chemicals is restricted in several countries, as they may be dangerous to human health [17]. Therefore, the search for new natural antioxidant sources has been greatly intensified. For this reason, there is a growing interest in the studies of natural additives as potential antioxidants. The antioxidant properties of many herbs and spices are reported to be effective in retarding the process of lipid peroxidation in oils and fatty foods and have gained the interest of many research groups. A number of studies on the antioxidant activities of various aromatic plants have been reported over the last 20 years $[18,19]$. Their aroma is associated with essential oils, complex mixtures of volatile compounds, dominated by mono- and sesquiterpenes. It is known that essential oils 
exhibit significant biological and pharmacological activities such as anti-inflammatory, antimicrobial, spasmolytic, stimulant effect on the CNS and the like. New research shows that they possess significant antitumor activity [20], and act as inhibitors of growth of breast tumors [21]. It was confirmed that essential oils of some aromatic plants possess a high antioxidant potential [22]. Widely used in the food industry to improve the flavor of foods.

In addition to essential oils, aromatic plants and characterized by the presence of plant phenolic compounds, primarily phenylpropanoids and coumarins which are proven to have multiple pharmacological activities. Studies of these secondary biomolecules have become intensified when some commercial synthetic antioxidants found to be expressed toxic, mutagenic and carcinogenic activities [23]. In addition, it was found that excessive production of oxygen radicals in the body initiates oxidation and degradation of polyunsaturated fatty acids. It is known that free radicals attack the highly unsaturated fatty acid of membrane system and induce lipid peroxidation, which is a key process in many pathological conditions, and one of the reactions caused by oxidative stress. Particularly vulnerable are the biological membrane lipids in the spinal cord and brain because they contain high oxiable polyunsaturated fatty acids. These features facilitate the formation of oxygen radicals involved in the processes of aging, Alzheimer's and Parkinson's disease, ischemic damage, arthritis, myocardial infarction, arteriosclerosis and cancer. Phenolic antioxidants "stop" oxygen free radicals and free radicals formed from the substrate by giving hydrogen atom or an electron. Some flavonoids have strong inhibitory effect on lipid peroxidation processes. This action is based on their ability to chelate transition metal ions, thereby preventing the formation of radicals (initiators of LP), caught radicals initiators of LP (ROS), scavenge lipid-alkoxyl and lipid-peroxyl radicals and regenerate $\alpha$-tocopherol by reduction of $\alpha$-tocopheryl radicals. Flavonoids have the following characteristics: 3 ', 4'dihydroxy group in ring B, or 4-keto and 3-hydroxy group in C ring, or 4'-keto group in C ring and 5-hydroxy group in A ring have the metal chelated properties (Figure 3.).

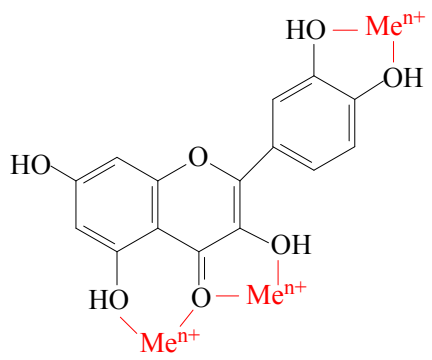

Figure 3. Possible places on flavonoids for chelating the transition metal ions in the process of lipid peroxidation.

Different metals have different binding affinity of the flavonoids [24]. Thus, for example, iron has the highest binding affinity for $3-\mathrm{OH}$ group of ring $\mathrm{C}$, then catechol group ring $\mathrm{B}$ and at the end of $5-\mathrm{OH}$ group of ring $\mathrm{A}$, while the copper ions bind to the first ring catechol group B [25]. Solubility of flavonoids in the lipid phase and the ability to penetrate the lipid 
membrane is small, since flavonoids in nature are mostly in the form of polar glycosides. Numerous tests of the inhibitory effects of flavonoids on lipid peroxidation were carried out on models of cell membranes. Based on these studies, it is assumed that quercetin and other flavonoids probably located on the surface membrane could easily capture radicals from the aqueous phase and thus prevent the initiation of LP. Thus located, flavonoids faster capture radicals initiators LP than $\alpha$-tocopherol, which is located within phospholipid bilayer and that the switch is a typical chain reaction. Prevention of initial attacks radicals from the aqueous phase to membrane phospholipids is essential in the antioxidant protection of biomembranes because free radicals are constantly generated in the aqueous phase of cellular and sub cellular structure [25,26].

In the present chapter, lipid peroxidation in a liposomal system was initiated by $\mathrm{Fe}^{2+}-$ ascorbic acid system and the effects of four different Lamiaceae species (Melittis melissophyllum, Marrubium peregrinum, Ocimum basilicum, and Origanum vulgare) extracts and essential oils were investigated. Particular attention was paid to the chemical composition of extracts and essential oils and their capability to reduce lipid peroxidation. The plant leaves were dried in air and ground in a mixer. Finely powdered material (200 g) was macerated three times in $70 \%$ methanol $(\mathrm{MeOH})$ with $4 \mathrm{~L}$ during a $24-\mathrm{h}$ period. The macerates were collected, filtered, and evaporated to dryness under vacuum. The residues were dissolved in water and successively extracted with four solvents of increasing polarity: ether $\left(\mathrm{Et}_{2} \mathrm{O}\right)$, chloroform $\left(\mathrm{CHCl}_{3}\right)$, ethyl acetate (EtOAc), and $n$-butanol $(n-\mathrm{BuOH})$. The extraction was carried out until a colorless extract was obtained. The residue was the aqueous extract. All of five extracts $\left(\mathrm{Et}_{2} \mathrm{O}, \mathrm{CHCl}_{3}, \mathrm{EtOAc}, n-\mathrm{BuOH}\right.$, and $\left.\mathrm{H}_{2} \mathrm{O}\right)$ were evaporated to dryness and then dissolved in $50 \%$ ethanol to make $10 \%(\mathrm{w}=\mathrm{v})$ solutions. Both, these and the diluted solutions, were further used for examination. Essential oil was made when air-dried plant material was submitted to hydrodistillation according to Eur. Pharm. 4 [27], using $n$-hexane as a collecting solvent. The solvent was removed under vacuum. The oils were dried over anhydrous sodium sulphate and kept at $+4{ }^{\circ} \mathrm{C}$. The inhibition of LP was determined by measuring the formation of secondary components (malondialdehyde) of the oxidative process, using liposomes as an oxidizable substrate [28-30]. However, because the thiobarbituric acid test is not specific for MDA, other non-lipid substances present in plant extracts, or peroxidation products other then malondialdehyde, could react positevely with TBA. These interfering compounds distort the results and therefore all the final results of investigated extracts have been corrected using the absorbances of the investigated extracts after the TBA-test (without liposomes) [31]. The commercial preparation of liposomes 'PROLIPO S' (Lucas-Meyer) $\mathrm{pH}=5-7$ was used as a model system of biological membranes. The liposomes, 225-250 $\mathrm{nm}$ in diameter, were obtained by dissolving the commercial preparation in demineralized water (1:10), in an ultrasonic bath.

\section{Lamiaceae (Labiatae) family}

The Lamiaceae family is one of the largest and most distinctive families of flowering plants, with about 220 genera and almost 4000 species worldwide [32]. Lamiaceae are best known for the essential oils common to many members of the family [33]. The family was 
established by De Jussieu in 1789 as the order Labiatae. This was the original family name, so given because the flowers typically have petals fused into an upper lip and a lower lip, the flower thus having an open mouth. Although this is still considered an acceptable alternative name, most botanists now use the name "Lamiaceae" in referring to this family. The main centre of diversity is the Mediterranean region to central Asia. Members are found in tropical and temperature regions [34]. All Lamiaceae are aromatic plants. The essential oil contains mainly monoterpenes, sesquiterpenes and phenylpropanoid compounds. Also, the plant species of Lamiaceae have been shown as rich sources of phenolic compounds mostly flavonoids and phenolic acids.

\subsection{Balm (Melittis melissophyllum L.)}

The name melittis of the genus derives from a Greek words Melissa or Melitta, meaning "honey bee" and refers to the properties of flowers of attracting these insects. The name melissophyllum of the species simply means "with leaves similar to melissa". This is a tall plant which likes shady places and is ideal for a sunny woodland edge or scrubby border, where it will be attractive to bees and other insects. Bastard balm is a strongly aromatic plant that smells like fresh mowed grass and has erect hairy stems. It blooms white with a large pinkish purple blotch on the lower lip. The flowers are hermaphrodite and get pollinated by bees and moths. It has oval, bluntly-toothed, leaves in opposite pairs up the stems. Bastard balm is a herb native to the Mediterranean region.

Main flavonoids in balm are glycosides of apigenin and luteolin. However, presence of some other flavonoids as kaempherol, quercetin (Figure 4.) and ramnocitrin have been also reported [35].<smiles>O=c1c(O)c(-c2ccc(O)c(O)c2)oc2cc(O)cc(O)c12</smiles><smiles>O=c1c(O)c(-c2ccc(O)cc2)oc2cc(O)cc(O)c12</smiles>

Figure 4. Structures of two flavonoids present in M. melissophyllum

Balm is characterized by the presence of the other important plant phenolic substances such as phenolic acids (caffeic, rosmarinic and chlorogenic acid) (Figure 5.).

Also, balm leaf is characterized by the presence of pentacyclic triterpenes (ursolic, pomolic and oleanolic acid) (Figure 6.). The main biopharmacological effects shared by ursolic and oleanolic acid are anti-inflammatory, hepatoprotective, antitumor, and antioxidative [36-39].

Essential oil is present in all parts of the plant. The largest amount of oil obtained from aerial parts of plants, harvested in late summer. Balm leaves contain no more than $0.13 \%$ of essential oil which is of complex and variable composition. Among the more than 50 
compounds identified to date, citronellal (dominantly the $(R)$ enantiomer), $\beta$-caryophyllene, -caryophyllene oxide, germacrene-D, nerol, geranial, citronellol, and geraniol amount to about $70 \%$ of the oil (Figure 7.) [40]. The composition is similar to that of lemongrass, but balm oil can be identified by its typical pattern of chiral compounds; for example, almost enantiomerically pure $(R)-(+)$-methyl citronellate is a good indicator of true balm oil. For distinguish between two oils there is used the carbon isotopic ratio (IRMS-isotope ratio mass spectrometry) [41]. The essential oil exhibits spasmolitic action and acts as a muscle relaxant, sedative, narcotic, antibacterial, and antifungal [42,43].<smiles>O=C(O)/C=C\c1ccc(O)c(O)c1</smiles><smiles>O=C(/C=C\c1ccc(O)c(O)c1)OCC(C(=O)O)c1ccc(O)c(O)c1</smiles>

Caffeic acid Rosmarinic acid<smiles>O=C(/C=C\c1ccc(O)c(O)c1)OC1CC(O)(C(=O)O)CC(O)C1O</smiles>

Chlorogenic acid

Figure 5. Structures of phenolic acids in M. Melissophyllum

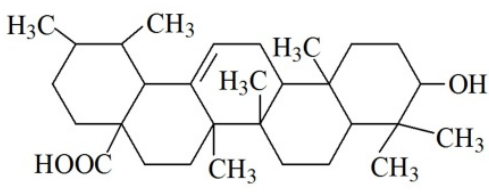

Ursolic acid<smiles>CC1CC(O)C(C)(C)C2CCC3(C)C(CC=C4C5CC(C)(C)CCC5(C(=O)O)CCC43C)C12</smiles>

Oleanolic acid

Figure 6. Structures of triterpenoids compounds present in M. melissophyllum leaves. 


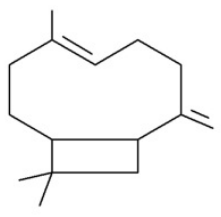

$\beta$-caryophyllene

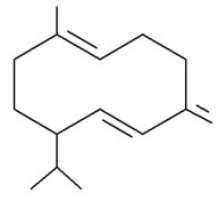

Germacrene D

Figure 7. Sesquiterpenes in M.melissophyllum leaves

Beneficial effects of plants introduced by ancient Greeks and Romans.There is overlap with the use of plants in folk medicine and science. In relation to its complex composition it has multiple medicinal effects. Its herb has wide applications in the folk medicine. Due to the soothing action balm leaves enters into the composition of tea for calming, which is recommended for hysteria and neuralgia. Balm leaves mixed with bitter herbs are a great tool to enhance appetite. Various preparations containing extract or essential oil balm leaves are used as an addition to baths against rheumatism. In the folk medicine of Belarus alcoholic extract is drunk for stomach ulcer and duodenum, to calm the pain in the stomach, intestines, the liver, heart, and women's diseases. Terpenes found in essential oil of balm leaves, have a relaxing and antiviral effects. Eugenol calms muscle spasms and destroy bacteria [44]. It is also used as a carminative and sedative. Recent results indicate that the balm extract acts as depressants and have sedative effect on central nervous system of mice [45]. In the folk medicine of central Italy inflorescences of this plant, called "Erba Lupa", were used under infusion as antispasmodic, against insomnia and eyes inflammations [46,47].

Our research on balm was recently extended to the comprehensive in vitro and in vivo studies of antioxidant properties of balm essential oil and extracts measuring their capability to reduce lipid peroxidation in liposomes and effect on some enzymes of antioxidant defense systems [48]. Investigation of balm essential oil showed that with increasing concentration of essential oil reduces the intensity of lipid peroxidation compared to hexane-control (Table 1). Also, only the most diluted solution of essential oil of balm $(0.213$ and $0.535 \mu \mathrm{g} / \mathrm{mL}$ ) has a weaker protective effect than the synthetic antioxidant BHT. The capability to reduce lipid peroxidation of essential oil was dose-dependent. This high inhibitory effect of balm essential oil was found to be in correlation with the content of monoterpene alcohols and ketones.

\begin{tabular}{|l|l|l|l|l|l|l|}
\cline { 2 - 7 } \multicolumn{1}{c|}{} & \multicolumn{7}{c|}{$\begin{array}{c}\text { Concentration } \\
(\mu \mathrm{g} / \mathrm{mL})\end{array}$} \\
\cline { 2 - 8 } \multicolumn{1}{c|}{} & BHT & $\mathbf{0 . 2 1 3}$ & $\mathbf{0 . 5 3 5}$ & $\mathbf{1 . 0 6 5}$ & $\mathbf{1 . 5 9 8}$ & $\mathbf{2 . 1 3 0}$ \\
\hline LP & 26.15 & 13.05 & 21.03 & 39.62 & 46.09 & 56.81 \\
\hline
\end{tabular}

Table 1. Inhibition of LP (\%) in $\mathrm{Fe}^{2+} /$ ascorbate system of induction by essential oil of balm leaves and BHT (as a positive control) in the TBA assay.

The protective effects on lipid peroxidation of balm extracts have been evaluated using the $\mathrm{Fe}^{2+} /$ ascorbate system of induction, by the TBA-assay (Table 2.). In general, all of the 
examined extracts (except $n$-BuOH extract) expressed strong antioxidant capacity and ability to reduce lipid peroxidation in liposomes. The largest inhibitory activity was exhibited by EtOAc and $\mathrm{H}_{2} \mathrm{O}$ extracts because the $5 \%$ solutions show better protective effect than BHT. All extracts of the highest concentrations (10\%) exhibited a better inhibitory effect than BHT. Protective activity of these extracts and its components towards $\mathrm{Fe}^{2+}$-dependent LP of liposomes can be explained by present of phenolic acids and flavonoids and their influence on antioxidative capacity of ascorbic acid, which doesn't show a strong antioxidative effect in lipid phase, but different phenolic compounds can result increase of its antioxidant activity [49].

\begin{tabular}{|l|c|c|c|c|c|c|}
\cline { 2 - 7 } \multicolumn{1}{c|}{} & \multicolumn{7}{c|}{ Extracts } \\
\hline Concentration & $\mathbf{B H T}$ & $\mathbf{E t}_{2} \mathbf{O}$ & $\mathbf{C H C l}_{\mathbf{3}}$ & $\mathbf{E t O A c}$ & $\boldsymbol{n}-\mathbf{B u O H}$ & $\mathbf{H}_{2} \mathbf{O}$ \\
\hline $\mathbf{1 \%}$ & 26.15 & 17.52 & 16.15 & 22.87 & -10.59 & 24.24 \\
\hline $\mathbf{5 \%}$ & 26.15 & 20.82 & 20.59 & 27.88 & -13.19 & 39.36 \\
\hline $\mathbf{1 0} \%$ & 26.15 & 26.40 & 28.40 & 38.47 & -18.52 & 41.32 \\
\hline
\end{tabular}

Table 2. Inhibition of $\mathrm{LP}(\%)$ in $\mathrm{Fe}^{2+} /$ ascorbate system of induction by extracts of balm leaves and $\mathrm{BHT}$ (as a positive control) in the TBA assay.

It is known that quercetin, like many other flavonoids, prevents oxidation of LDL cholesterol, and its anti-inflammatory activity comes from inhibition of the enzyme lipooxigenase and inhibition of inflammatory mediators [50]. Kaempferol acts synergistically with quercetin to reduce the proliferation of malignant cells, and treatments are a combination of quercetin and kaempherol efficient than their single use [51]. It is, also, known that rutin has strong antioxidant effects, as well as a feature to built chelates with metal ions (e.g. iron) and reduces the Fenton reaction in which the resulting harmful oxygen radicals. It is supposed to stabilize vitamin C. If rutin is taken together with vitamin $C$, increases the activity of ascorbic acid [52]. In addition, HPLC-DAD analysis showed that the aqueous extract, in large quantities, present phenolic acids (rosmarinic, chlorogenic and caffeic acid), which are known antioxidants. It was determined that rosmarinic acid has stronger antioxidant activity than vitamin E. Rosmarinic acid prevents cell damage caused by free radicals and reduce the risk of cancer and atherosclerosis. In contrast to the histamines, rosmarinic acid prevents activation of the immune system cells that cause swelling and fluid collection. Also, it is known that the caffeic acid by far surpassing other antioxidants because it reduces the production of $\alpha$-toxin for more than 95\% [35]. Furthermore, it can be supposed that the reduction process of lipid peroxidation is caused, besides flavonoids, also by triterpenoids acids (especially ursolic, oleanolic, and pomolic acid) since non-polar extracts $\left(\mathrm{Et}_{2} \mathrm{O}\right.$ and $\left.\mathrm{CHCl}_{3}\right)$ also exhibited high antioxidant potential [39]. The $n-\mathrm{BuOH}$ extract shows a prooxidative effect that is increased by increasing concentration of added extract. It can be supposed that compounds with polar groups were extracted by $n-\mathrm{BuOH}$, and are present in high concentration in the extract. It is notable that molecules which show antioxidant activity, when they are present in high concentration, might behave as prooxidants [53], so $n$ - $\mathrm{BuOH}$ extract of balm leaves probably have this kind of activity. The antioxidant activities of all extracts of balm leaves were dose dependent. 
The represented antioxidant activity results show that extracts of examined plant species, especially EtOAc and $\mathrm{H}_{2} \mathrm{O}$ extracts are efficient in the protection of tissues and cells from oxidative stress. Anyway, according to variations in regard to antioxidant activity of tested by different in vitro models, there are also requiste in vivo test that would confirm the capability of extracts to reduce the lipid peroxidation. In vivo tests are also necessary because a lot of plant phenols are biotransformed during their active metabolism. In vivo effects are evaluated on LP in the mice liver (Table 3.) and blood hemolysate (Table 4.) after treatment with examined balm extracts, or in combination with carbon tetrachloride $\left(\mathrm{CCl}_{4}\right)$.

\begin{tabular}{|l|c|c|c|c|c|c|}
\hline Parameter & Control & $\mathbf{E t}_{2} \mathbf{O}$ & $\mathbf{C H C l}_{3}$ & EtOAc & $n-\mathbf{B u O H}$ & $\mathbf{H}_{2} \mathbf{O}$ \\
\hline $\mathbf{L P}$ & $7.19 \pm 0.23$ & $7.36 \pm 0.21$ & $7.91 \pm 0.19$ & $6.71 \pm 0.16$ & $7.12 \pm 0.23$ & $6.19 \pm 0.27$ \\
\hline $\mathbf{L P}+\mathbf{C C l}_{4}$ & $8.91 \pm 0.29$ & $7.12 \pm 0.21$ & $7.06 \pm 0.24$ & $6.92 \pm 0.17$ & $6.98 \pm 0.24$ & $6.81 \pm 0.24$ \\
\hline
\end{tabular}

Table 3. Effect of extracts of balm leaves on intensity of lipid peroxidation (nmol malondialdehyde/mg of proteines) in liver homogenate before and after treatment with $\mathrm{CCl}_{4}$

As compared with control, intensity of LP is statistically significant reduced during the treatment with ethylacetate and water extracts of balm leaves. The result derived by treatment with ethylacetate and water extracts is in according with amounts got in vitro experiment. Using $\mathrm{CHCl}_{3}$ extract leads to a significant increase of LP intensity, whereas the other two extracts had no effect on this parameter. All extracts of balm leaves combine with $\mathrm{CCl}_{4}$ have showed a statistically significant decrease of LP intensity, and this behavior of the extract probably results from the presence of secondary biomolecules like flavonoids and phenolic acids. Handa et al. [54] determined that secondary biomolecules such as flavonoids, xanthones and tannins in combination with $\mathrm{CCl}_{4}$ have protective effects on liver. Phenolic components present in balm leaves (rutin, luteolin, kaempherol) are known as strong inhibitors of $\mathrm{CCl}_{4}$ induced LP [55]. Flavonoids could affect the initiation phase of lipid peroxidation, where they influence the metabolism of $\mathrm{CCl}_{4}$, they scavenge the free radicals, or they decrease the microsomal enzyme systems that are claimed for $\mathrm{CCl}_{4}$ metabolism [56]. In continuation of this process, flavonoids can scavenge lipoperoxides and their radicals or they can act as chelating agents for $\mathrm{Fe}^{2+}$ ion, and in this way can stop Fenton reactions [57]. Furthermore, Afanas'ev et al. [28] found that quercetin and rutin exhibited a high inhibitory effect on the $\mathrm{Fe}^{2+}$-induced liposomal LPx and NADPH-dependent $\mathrm{CCl}_{4}$-induction LPx in liver microsomes. Luteolin, one of the main active component in the balm, is responsible for the inhibitory effect on the former reaction. In addition to the above-mentioned mechanism (chelate formation with $\mathrm{Fe}^{2+}$ ) it is possible that these compounds (of flavonoid type) act as scavengers of $\mathrm{OH}$ radicals, whereby they are transformed in the corresponding radical form which is stabilized by resonance. On the basis of these results, it can be concluded that all of extracts of balm leaves showed protection effect in relation to the $\mathrm{CCl}_{4}$-induced lipid peroxidation.

Similar results were obtained during examining the effects of extracts of bastard balm on LP in blood hemolysate in mice (Table 4.). Three extracts, $\mathrm{CHCl}_{3}, \mathrm{EtOAc}$ and $\mathrm{H}_{2} \mathrm{O}$, induced a significant decrease of LP intensity, while $\mathrm{Et}_{2} \mathrm{O}$ and $n-\mathrm{BuOH}$ ones decreased the level of this enzyme insignificantly. 


\begin{tabular}{|l|c|c|c|c|c|c|}
\hline Parameter & Control & $\mathbf{E t}_{2} \mathbf{O}$ & $\mathbf{C H C l}_{3}$ & EtOAc & $n-\mathbf{B u O H}$ & $\mathbf{H}_{2} \mathbf{O}$ \\
\hline $\mathbf{L P}$ & $4.81 \pm 0.24$ & $4.59 \pm 0.28$ & $3.78 \pm 0.17$ & $2.96 \pm 0.13$ & $4.74 \pm 0.19$ & $4.07 \pm 0.24$ \\
\hline $\mathbf{L P}+\mathbf{C C l}_{4}$ & $5.11 \pm 0.24$ & $5.31 \pm 0.17$ & $4.92 \pm 0.21$ & $3.02 \pm 0.24$ & $5.17 \pm 0.25$ & $2.98 \pm 0.12$ \\
\hline
\end{tabular}

Table 4. Effect of extracts of balm leaves on intensity of lipid peroxidation (nmol malondialdehyde/mL erythrocytes) in blood hemolysate before and after treatment with $\mathrm{CCl}_{4}$

The LP value showed a statistically insignificant increase with $\mathrm{CCl}_{4}$-treated animals compared with the untreated ones. A clear protective effect was seen in experimental animals administered $\mathrm{H}_{2} \mathrm{O}$ extract and $\mathrm{CCl}_{4}$ compared with untreated animals. Furthermore, EtOAc extract also significantly decreased the activity of $\mathrm{LP}$, while $\mathrm{Et}_{2} \mathrm{O}, \mathrm{CHCl}_{3}$ and $n$ - $\mathrm{BuOH}$ extracts did not change notably the levels of lipid peroxidation. These results suggest that these two extracts (EtOAc and $\mathrm{H}_{2} \mathrm{O}$ ) had a protective effect. According to the literature data [58], the reduction of the serum LP might be the result of antioxidant activity of several classes of plant phenolic constituents, such as cinnamic acids (ferulic, caffeic, and chlorogenic), flavonoids and biflavonoids, 1,3,6,7-tetrahydroxyxynthones, and acylphoroglycinols such as hyperforin and adhyperforin. Cock and Samman [59] showed that quercetin and rutin and their glycosides show strong inhibitory effect in respect of LP. The observed differences in the action of particular balm extracts are probably due to the different contents of flavonoids, but the potential protective effects of some other groups of compounds can not be ruled out.

\subsection{Horehound (Marrubium peregrinum L.)}

Marrubium genus includes about 40 species. Species of this genus growing in dry pastures, abandoned the places along the roads in central and southern Europe, but also in North Africa, in parts of Asia and the Americas. Horehound is a perennial plant with a rectangular stem, branched in the upper part. Rhizomes of this species are ligneous, leaves oblong, flowers grouped in loose inflorescence [60]. A common plant blooms from July to September and harvested in that period. It has a bitter and pungent taste and smell. It is the drug of Herba Marrubii albi. This plant doesn `t require special conditions for growth.

In previous phytochemical investigations on M. peregrinum, different groups of chemicals were isolated: flavones (apigenin and luteolin) [61] (Figure 8.), flavonols (kaempferol) [62], glycosylated flavonoids (quercetin-3-O- $\beta$-D-rutinoside, naringenin-7-O- $\beta$-D-glucoside, kaempferol-3-O- $\beta$-D-rutinoside, quercetin-3-O- $\beta$-D-glucoside) [63], caffeic acid derivatives [64], and four diterpenoids (peregrinin, peregrinol, marrubiin and premarrubiin) [65]. T. Hennebelle et al. [66] have established the presence of acteoside, forsythoside B, arenarioside and terniflorine (apigenin-7-O-[6"-E-p-coumaroyl] $\beta$-D-glucopyranoside) in the $\mathrm{MeOH}$ extract of $M$. peregrinum.

Marrubium peregrinum essential oil yield between 0.02-0.07\% [67]. Dominant monoterpenes are: $\alpha$-pinene, sabinene, limonene, camphene and $\alpha$-terpinolene. In a Greek sample, $\beta$ phellandrene, epi-bicyclosesquiphellandrene and bicyclogermacrene proved to be the major compounds [68], whereas the essential oil of a sample from Central Europe was rich in $\beta$ - 
caryophyllene and its oxide, bicyclogermacrene and germacrene $D$ [69]. The main sesquiterpene compounds are Z- and E- $\beta$-farnesene $(\sim 12 \%), \beta$-caryophyllene $(\sim 8.5 \%)$, heksahidrofarnesil acetone $(\sim 6.5 \%)$, spathullenol $(\sim 5 \%)$ i germacrene D ( 4.5\%) (Figure 9.) [68].<smiles>O=c1cc(-c2ccc(O)c(O)c2)oc2cc(O)cc(O)c12</smiles>

luteolin<smiles>O=c1cc(-c2ccc(O)cc2)oc2cc(O)cc(O)c12</smiles>

apigenin

Figure 8. Figure 8. Structures of two main flavonoids in M. peregrinum.

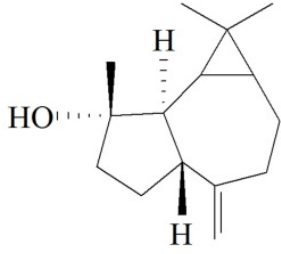

spathullenol

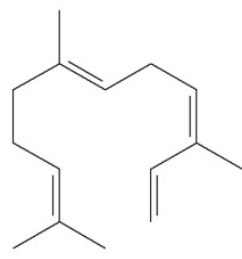

$Z$ - and E- $\beta$-farnesene

Figure 9. Main constituents of M. peregrinum essential oil

Some species of Marrubium are used in traditional and modern medicine. Many studies have shown various activities in this genus, such as hypoglycemic effect, anti-schistosoma, antioxidant, calcium channel blocker and hypotensive activity [70]. As a medicinal plant, $M$. peregrinum have been employed against vascular diseases (antihypertensive, antispasmolitic) [61].

In our comprehensive study of chemical and biochemical investigation of $M$. peregrinum from three different locations (Backo Gradiste-Rimski Sanac (No 1.); Novi Knezevac (No 2.) and Senta (No 3.)), we have identified more than 40 compounds in essential oil of $M$. peregrinum (44 for $M$. peregrinum from Senta locality, 42 for $M$. peregrinum from Novi Knezevac locality and 41 for M. peregrinum from Rimski Sanac locality, representing $96.15 \%$, $87.60 \%$ and $83.66 \%$ of the total oil contents, respectively), in which dominant compounds were $\beta$-caryophyllene (13.20-17.99\%), bicyclogermacrene (6.42-9.80\%) and germacrene-D (6.79-9.05\%). Besides sesquiterpene hydrocarbons, oxygenated sesquiterpenes, spathulenol $(3.76-5.78 \%)$ and caryophyllene oxide (3.73-4.78\%) are also present in relevant quantities. However, we must point out that the amounts of these components in essential oil from different localities are very different. Essential oil obtain from plant collected in Senta is the richest of sesquiterpene hydrocarbons $(62.71 \%)$, while oxygenated sesquiterpenes are most represented (11.84\%) in essential oil from plants collected in the Rimski Sanac area. 


\begin{tabular}{|c|c|c|c|c|c|c|}
\hline & \multicolumn{6}{|c|}{$\begin{array}{c}\text { Concentration } \\
(\mu \mathrm{g} / \mathrm{mL})\end{array}$} \\
\hline & BHT & 0.213 & 0.535 & 1.065 & 1.598 & 2.130 \\
\hline M. peregrinum (No 1.) & 26.15 & 12.24 & 26.00 & 35.36 & 44.26 & 56.18 \\
\hline M. peregrinum (No 2.) & 26.15 & 19.15 & 20.05 & 39.37 & 52.14 & 61.18 \\
\hline M. peregrinum (No 3.) & 26.15 & 21.17 & 37.02 & 55.81 & 65.16 & 71.32 \\
\hline
\end{tabular}

Table 5. Inhibition of LP (\%) in $\mathrm{Fe}^{2+} /$ ascorbate system of induction by essential oil of M. peregrinum from three different location, and BHT (as a positive control) in the TBA assay.

Also, our study showed that all of the examined essential oils express strong antioxidant activity and capability to reduce lipid peroxidation (Table 5.). The largest inhibitory activity was exhibited by essential oil from plant collected at Senta locality (No. 3.). Solution of all concentrations, except the most diluted $(0.213 \mu \mathrm{g} / \mathrm{mL})$, have exhibited a stronger protective effect (from 37.02 to $71.32 \%$ of inhibition of LP) than BHT (26.15\%). The other two essential oils (from Rimski sanac and Novi Knezevac), at higher concentration (from 1.065 to 2.130 $\mu \mathrm{g} / \mathrm{mL})$, have also exhibited more intense protective effect than BHT [71].

The effect of crude $\mathrm{MeOH}$ extracts of $M$. peregrinum was preliminarily determined from the three localities. There were taken three concentrations of $\mathrm{MeOH}$ extracts $(1,5$, and $10 \%$ extracts). All of the examined extracts expressed stronger antioxidant capacity as compared to the $50 \%$ solution of $\mathrm{MeOH}$. In particular, the largest inhibitory activity was established by the $\mathrm{MeOH}$ extracts of $M$. peregrinum collected from Senta locality. Also, the best results were obtained using solutions of the highest concentrations [72]. Because of all this there was carried out successive extractions of $M$. peregrinum from all three localities, and for further work $10 \%$ extracts are prepared. Successive extraction was performed as the extraction of antioxidant substances of different chemical structure, was achieved using solvents of different polarity. Numerous investigations of qualitative composition of plant extracts revealed the presence of high concentration of phenols in the extracts obtained using polar solvents [73]. The extracts that perform the highest antioxidant activity have the highest concentration of phenols. Phenols are very important plant constituents because of their scavenging ability on free radicals due to their antioxidant action [74]. The examination of capability to reduce intensity of lipid peroxidation of plant extracts from M. peregrinum showed different values (Table 6.). The first two extracts ( $\mathrm{Et}_{2} \mathrm{O}$ and $\mathrm{CHCl}_{3}$ ) obtained from plants from all three locality are exhibited weaker protective effect than BHT, while the other three extracts (EtOAc, $n$ - $\mathrm{BuOH}$ and $\mathrm{H}_{2} \mathrm{O}$ ) showed better protective properties than synthetic antioxidant.The largest inhibitory activity, again, was exhibited by the EtOAc and $\mathrm{H}_{2} \mathrm{O}$ extracts of $M$. peregrinum collected from Senta locality.

Obtained results can be related to the experiments in which the total amount of flavonoids was determined, which show that EtOAc and $\mathrm{H}_{2} \mathrm{O}$ extracts from Senta locality contains the largest amounts of total flavonoids, namely of luteolin, either being present as free or in the form of its glucosides. The suggested mechanism of flavonoid antioxidative action is as follows: the double bond in position 2, 3 is conjugated with $\mathrm{C}_{4}$-carbonyl group, and free $\mathrm{OH}$ groups $\left(\mathrm{C}_{5}, \mathrm{C}_{3}\right.$ and $\left.\mathrm{C}_{7}\right)$ can form chelates with ions of d-elements. Once formed, complex 
with $\mathrm{Fe}^{2+}$ ion prevents formation of $\mathrm{OH}^{\bullet}$ radicals in Fenton's reaction [59]. Also, luteolin is thought to play an important role in the human body as an antioxidant, a free radical scavenger, an agent in the prevention of inflammation, a promoter of carbohydrate metabolism, and an immune system modulator. These characteristics of luteolin are also believed to play an important part in the prevention of cancer. Multiple research experiments describe luteolin as a biochemical agent that can dramatically reduce inflammation and the symptoms of septic shock [75]. Furthermore, it is well known that some other flavonoids isolated from $M$. peregrinum possess certain biological and pharmacological activity. For example, apigenin, one of the flavonoids present in $M$. peregrinum, was shown to express strong antioxidant effects, increasing the activities of antioxidant enzymes and, related to that, decreasing the oxidative damage to tissues [61].

\begin{tabular}{|l|c|c|c|c|c|c|}
\cline { 2 - 7 } \multicolumn{1}{c|}{} & \multicolumn{7}{c|}{ Extracts } \\
\hline & $\mathbf{B H T}$ & $\mathrm{Et}_{2} \mathbf{O}$ & $\mathbf{C H C l}_{3}$ & EtOAc & $n$-BuOH & $\mathbf{H}_{2} \mathbf{O}$ \\
\hline M. peregrinum (No 1.) & 26.15 & 9.38 & 14.22 & 29.41 & 27.39 & 32.35 \\
\hline M. peregrinum (No 2.) & 26.15 & 14.27 & 21.19 & 29.54 & 26.83 & 37.55 \\
\hline M. peregrinum (No 3.) & 26.15 & 17.11 & 23.52 & 38.83 & 28.73 & 41.18 \\
\hline
\end{tabular}

Table 6. Inhibition of LP (\%) in $\mathrm{Fe}^{2+} /$ ascorbate system of induction by extracts of $M$. peregrinum and BHT (as a positive control) in the TBA assay.

\subsection{Basil (Ocimum basilicum L.)}

Basil is originally native to India and other tropical regions of Asia, having been cultivated there for more then 5.000 years. Ocimum genus includes about 150 species [76]. There are many varieties of Ocimum basilicum, as well as several related species or species hybrids also called basil. These varieties differ in morphological and general structure, and also in the content and composition of essential oil. The chemotype is determined by chemical composition of essential oil and it is basic for chemotaxonomy within the genus Ocimum and species Ocimum basilicum [77].

The word market has several types of essential oils that differ in chemical structure, composition and fragrance. The dominant compounds of basil essential oil occur in two different biochemical pathways: phenylpropanoids (methyl chavicole, eugenol, methyl eugenol, and methyl cinnamate) through shicimic acid, and terpenoids (linalool and geraniol) through mevalonic acid. Based on chemical content, basils can be divided into four groups: European (French) O. basilicum (contains lower amounts of phenols); Exotic (contains methyl chavicol (40-80\%)); Reunion and Javanean. European type of essential oil is the finest quality, has the finest fragrance and the highest price in the market. Other components that can be found in higher concentrations in this type of oil are: linalool, methyl chavicol (estragole) (Figure 10.), 1,8-cineole, eugenol, geraniol, germacrene D, $\alpha$-terpinolene, $\beta$-caryophyllene, ocimene, sabinene, thujone, and $\gamma$-terpinene [78].

Among phenolic constituents flavonoids and their glucosides are dominant. The major flavonoids are: quercetin, kaempferol, apigenin, luteolin and rutin. Quercetin-3-O- 
diglucoside and kaempferol-3-O- $\beta$-rutinoside have been also identified. Beside, basil is rich in triterpenoid acids (ursolic and oleanolic), cinnamic acid (caffeic and rosmarinic), vitamin $\mathrm{C}$ and $\beta$-carotene, as well with calcium, copper, magnesium, sodium and potassium [79].<smiles>C=C[C@](C)(O)CCC=C(C)C</smiles>

linalool<smiles>C=CCc1ccc(OC)cc1</smiles>

methyl chavicol

Figure 10. Main constituents of O. basilicum essential oil

Basilici herba has been used in traditional and homeopathic medicine to treat number of diseases. Essential oil (Basilici aetheroleum) extracted from fresh leaves and flowers can be used as aroma additives in foods, pharmaceuticals, and cosmetics [80]. Traditionally, basil has been used as a medicinal plant in the treatment of headaches, coughs, diarrhea, constipation, warts, worms, and kidney malfunction. Major aroma compounds from volatile extracts of basil present anti-oxidative activity [81]. Among the many studies to determine the antioxidant activities of basil, most have focused mainly on the antioxidant activities of crude extracts, using methanol, acetone, or water as a solvent $[82,83]$.

\begin{tabular}{|l|c|c|c|c|c|c|}
\cline { 2 - 7 } \multicolumn{1}{c|}{} & \multicolumn{7}{c|}{$\begin{array}{c}\text { Concentration } \\
(\boldsymbol{\mu g} / \mathrm{mL})\end{array}$} \\
\cline { 2 - 7 } \multicolumn{1}{c|}{} & BHT & $\mathbf{0 . 2 1 3}$ & $\mathbf{0 . 5 3 5}$ & $\mathbf{1 . 0 6 5}$ & $\mathbf{1 . 5 9 8}$ & $\mathbf{2 . 1 3 0}$ \\
\hline LP & 26.15 & 24.12 & 35.17 & 48.41 & 64.13 & 79.14 \\
\hline
\end{tabular}

Table 7. Inhibition of LP (\%) in $\mathrm{Fe}^{2+} /$ ascorbate system of induction by essential oil of basil leaves and $\mathrm{BHT}$ (as a positive control) in the TBA assay.

In our investigation, the examined essential oil expressed strong antioxidant activity (Table 7.). Solutions of all concentrations, except the most diluted $(0.213 \mu \mathrm{g} / \mathrm{mL})$, have exhibited a stronger protective effect (from 35.17 to $79.14 \%$ of inhibition of LP) than BHT $(26.15 \%)$. The largest inhibitory activity was achieved by using the solution of the highest concentration. For the inhibition of LP, the most responsible compounds were the oxygenated phenolic monoterpens (methyl chavicole) and the mixture of mono- and sesquiterpene hydrocarbons. These findings are in correlation with the earlier published data on the antioxidant activities of the investigated essential oil and selected oil components $[84,85]$. 


\begin{tabular}{|l|c|c|c|c|c|c|}
\cline { 2 - 7 } \multicolumn{1}{c|}{} & \multicolumn{7}{c|}{ Extracts } \\
\hline Concentration & BHT & $\mathrm{Et}_{2} \mathrm{O}$ & $\mathrm{CHCl}_{3}$ & EtOAc & $n-\mathrm{BuOH}$ & $\mathrm{H}_{2} \mathrm{O}$ \\
\hline $\mathbf{1 \%}$ & 26.15 & -0.87 & -0.86 & 37.42 & 26.31 & 31.74 \\
\hline $\mathbf{5 \%}$ & 26.15 & -0.94 & -0.89 & 38.91 & 27.06 & 35.29 \\
\hline $\mathbf{1 0} \%$ & 26.15 & -1.01 & -1.04 & 41.56 & 28.83 & 36.54 \\
\hline
\end{tabular}

Table 8. Inhibition of LP (\%) in $\mathrm{Fe}^{2+} /$ ascorbate system of induction by extracts of basil leaves and BHT (as a positive control) in the TBA assay.

The data presented in Table 8. show that the last three extracts of O. basilicum (EtOAc, n$\mathrm{BuOH}$ and $\mathrm{H}_{2} \mathrm{O}$ ) reduced the intensity of lipid peroxidation, while the first two extracts $\left(\mathrm{Et}_{2} \mathrm{O}\right.$ and $\left.\mathrm{CHCl}_{3}\right)$ increased the intensity of $\mathrm{LP}$, but statistically insignificant. The largest inhibitory activity was exhibited by ethyl acetate extract. High inhibitory effect of this three extracts can be related to the presence of the amount of total phenolic compounds and content of total flavonoids in the extracts, because a considerably content of total phenolic compounds and total flavonoids was determined in EtOAc and $\mathrm{H}_{2} \mathrm{O}$ extract of O. basilicum. Preliminary 2D-TLC (Two Dimensional - Thin Layer Chromatography) analysis showed that the dominant flavonoid in the EtOAc extract of O. basilicum is derivative of quercetin. It is known that quercetin shows high antioxidant activity because of present $\mathrm{OH}$ groups in position 3' ring B (includes a 3', 4'-dihydroxy group). In the same experiment we established the presence of caffeic acid and its derivatives in the $\mathrm{H}_{2} \mathrm{O}$ extract, which has two hydroxyl groups in ortho position. This was confirmed once again that the antioxidant capacity depends not only on quantity, but also depends on of the type of phenols and flavonoids present in the extracts. However, in extracts of O. basilicum higher content of total phenols and flavonoids from the EtOAc extract had an $\mathrm{H}_{2} \mathrm{O}$ extract. From all this it can be assumed that the polarity of flavonoid components affects their ability to inhibit the process of LP. Specifically, in this test we used liposomes as a model system of biological membranes, and the least polar flavonoids present in the EtOAc extract could help to approach the scene and engage in the process of defense from the LP, compared to more polar compounds that are found in $\mathrm{H}_{2} \mathrm{O}$ extract. A little less of total flavonoids was determined in $n$-BuOH extracts, while the smallest quantity of these compounds was found in $\mathrm{Et}_{2} \mathrm{O}$ and $\mathrm{CHCl}_{3}$ extracts. Differences in the amount of total phenolic compounds and flavonoid content between extracts can be explained by different number of secretory structures in various plant tissues [86]. Furthermore, the obtained results could be related to the protective role of phenolics, especially the flavonoid aglycones, in plants collected on the outskirts of big cities. One of the functions of these biomolecules, which are produced in response to ecological stress factors like pollution, is to serve as UV-B filters in plants [87]. It was established that flavonoids act as mighty scavengers of free radicals [88]. Different flavonoids inhibit LP in vitro and the most pronounced effect is exhibited by quercetin whose presence is found in extracts of O. basilicum using 2D-TLC [89]. More investigation is required to explain the enhanced production of phenolics in certain geographic areas [90]. Also, from the presented results we can conclude that the increase in concentration of the extracts does not significantly affect the inhibition of lipid peroxidation. 


\subsection{Oregano (Origanum vulgare L.)}

Origanum is one of the most variable genera of Lamiaceae family. Originates from Europe, but is now cultivated throughout the world including USA, India and South America. This is an extremely variable species with several subspecies and named cultivars grown for ornamental, culinary and medicinal uses. Oregano is a bushy, semi-woody sub-shrub with upright or spreading stems and branches. Some varieties grow in mound like mats, spreading by underground stems (called rhizomes), and others with a more upright habit. The aromatic leaves are oval-shaped. Oregano will grow in a $\mathrm{pH}$ range between 6.0 (mildly acid) and 9.0 (strongly alkaline) with a preferred range between 6.0 and 8.0. The flowers are purple, 3-4 mm long, produced in erect spikes.

As the other three Lamiaceae species oregano is characterized by the presence of essential oil, flavonoids, phenolic acids (caffeic, chlorogenic and rosmarinic), triterpenoid acids (oleanolic and ursolic) and tannins. The oregano essential oil yield between $0.35-0.55 \%$ [91]. According to Arnold et al. [92], the content of essential oil in Origanum ssp. may come up even to $8.8 \%$. Essential oils obtained from different parts of plant have a similar chemical profile. The dominant components are oxygenated phenolic monoterpenes thymol and carvacrol (Figure 11.), as well as sabinene, linalool, terpine-4-ol, $\alpha$-pinene, caryophyllene, caryophyllene-oxide and 1,8-cineole.
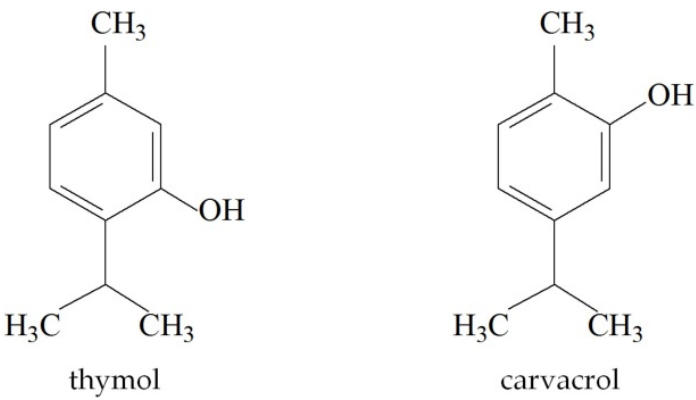

Figure 11. Oxygenated phenolic monoterpens from O. vulgare essential oil

According to Duke [93], flavonoids are found in the leaves and whole plant, mostly as kaempferol, quercetin, apigenin, luteolin and rutin. Beside, oregano is rich in apigenin-7-O$\beta$-D-glucoside and luteolin-7-O- $\beta$-D-glucuronide. In oregano flavanon naringenin and flavanon glucoside (naringin), have also been identified (Figure 12.).

Most of the healing properties are attributed to the essential oil and flavonoids. It has been widely used in agricultural, pharmaceutical and cosmetic industries as a culinary herb, flavoring substances in food products, alcoholic beverages and perfumery for its spicy fragrance [94]. Regarding the nonvolatile components, the extracts of oregano have the most effective antioxidant activity among aromatic herbs [95]. Oregano family, is widely known as possessing therapeutic properties (diaphoretic, carminative, antispasmodic, antiseptic, tonic) being used in traditional medicine systems in many countries. Different groups of 
researchers $[96,97]$ studied oregano alcohol extracts. The antioxidant effect of the mentioned extracts is generally due to the presence of rosmarinic and caffeic acid [98].<smiles>O=C1CC(c2ccc(O)cc2)Oc2cc(O)cc(O)c21</smiles>

naringenin

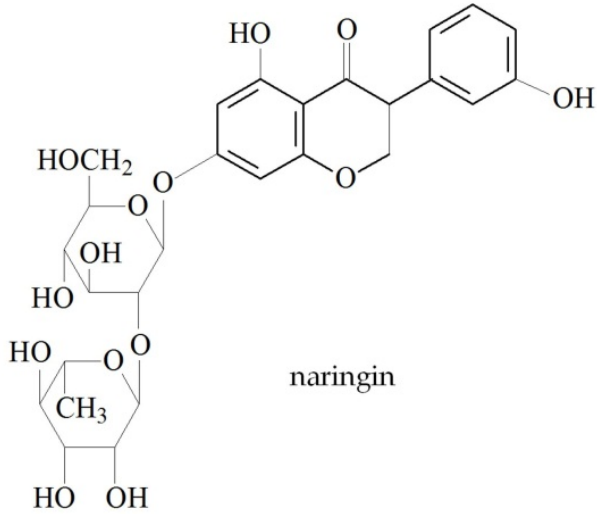

Figure 12. Structures of main flavonoids of O. vulgare

\begin{tabular}{|l|c|c|c|c|c|c|}
\cline { 2 - 7 } \multicolumn{1}{c|}{} & \multicolumn{6}{|c|}{$\begin{array}{c}\text { Concentration } \\
(\boldsymbol{\mu g} / \mathbf{m L})\end{array}$} \\
\cline { 2 - 7 } \multicolumn{1}{c|}{} & BHT & $\mathbf{0 . 2 1 3}$ & $\mathbf{0 . 5 3 5}$ & $\mathbf{1 . 0 6 5}$ & $\mathbf{1 . 5 9 8}$ & $\mathbf{2 . 1 3 0}$ \\
\hline LP & 26.15 & 17.31 & 24.35 & 37.17 & 49.58 & 51.13 \\
\hline
\end{tabular}

Table 9. Inhibition of $\mathrm{LP}(\%)$ in $\mathrm{Fe}^{2+} /$ ascorbate system of induction by essential oil of oregano leaves and BHT (as a positive control) in the TBA assay.

Our tests showed that only concentrated solutions of essential oil exhibit a greater ability to inhibit LP in liposomes of synthetic antioxidant BHT. The antioxidant activities were dose dependent, but it is noticeable that the values obtained using two most concentrated solution of essential oils $(1.598$ and $2.130 \mu \mathrm{g} / \mathrm{mL})$ are very close $(49.58$ and $51.13 \%$ of inhibition of LP). For the inhibition of LP, the most responsible compounds were the oxygenated phenolic monoterpens (thymol and carvacrol) and the mixture of mono- and sesquiterpene hydrocarbons [98].

\begin{tabular}{|l|c|c|c|c|c|c|}
\cline { 2 - 7 } \multicolumn{1}{c|}{} & \multicolumn{7}{c|}{ Extracts } \\
\hline Concentration & $\mathbf{B H T}$ & $\mathbf{E t}_{2} \mathbf{O}$ & $\mathbf{C H C l}_{3}$ & $\mathbf{E t O A c}$ & $n-\mathbf{B u O H}$ & $\mathbf{H}_{2} \mathbf{O}$ \\
\hline $\mathbf{1 \%}$ & 26.15 & -0.46 & -0.92 & 24.17 & 11.31 & 13.58 \\
\hline $\mathbf{5 \%}$ & 26.15 & -0.77 & -0.94 & 26.04 & 14.57 & 16.49 \\
\hline $\mathbf{1 0} \%$ & 26.15 & -0.91 & -0.97 & 30.28 & 19.78 & 23.24 \\
\hline
\end{tabular}

Table 10. Inhibition of $\mathrm{LP}(\%)$ in $\mathrm{Fe}^{2+} /$ ascorbate system of induction by extracts of oregano leaves and BHT (as a positive control) in the TBA assay.

The data presented in Table 10. show that the last three extracts of O. vulgare (EtOAc, n$\mathrm{BuOH}$ and $\mathrm{H}_{2} \mathrm{O}$ ) reduced the intensity of lipid peroxidation while the first two extracts $\left(\mathrm{Et}_{2} \mathrm{O}\right.$ and $\mathrm{CHCl}_{3}$ ) have prooxidative effect (but not statistically significant). The largest inhibitory 
activity was exhibited by ethyl acetate extract. High inhibitory effect of this extract and its components towards $\mathrm{Fe}^{2+}$-dependent LP of liposomes can be related to the presence of flavonoids in the extract. It was established that flavonoids that antiradical potential of flavonoids are the most pronounced towards $\mathrm{OH}$, peroxy- and alkoxy radicals, which are formed in the process of lipid peroxidation [99]. Also, these results are consistent with 2DTLC analysis which showed that the dominant component of the EtOAc extract was kaempferol monoglycoside, while the $\mathrm{H}_{2} \mathrm{O}$ extract contains multiple kaempferol diglycosides. From the literature it is known that additional glycosylation reduces the antioxidant activity and capability to reduce lipid peroxidation [100].The antioxidant and prooxidant activities of all extracts of oregano leaves were dose dependent.

\section{Conclusions}

It was found that excessive production of oxygen radicals in the body initiates oxidation and degradation of polyunsaturated fatty acids. It is known that free radicals attack the highly unsaturated fatty acid of membrane system and induce lipid peroxidation. Since lipid peroxidation causes oxidative damage to cell membranes and all other systems that contain lipids, in any investigation of total antioxidative activity of extracts and essential oils it is necessary to investigate their effects on lipid peroxidation. Some substrates (for example liposomes) are used more frequently than others, mainly because of the simplicity of the methods involved. In this way we get very useful information to direct future research. The results of our in vitro assays of examined four different Lamiaceae species extracts expressed significant protective effects on LP, which was found to be correlated to different compounds. It can be concluded that ethyl acetate and water proved to be the best solvent for extraction of plant material. Also, a very strong protective activity of the EtOAc and $\mathrm{H}_{2} \mathrm{O}$ extracts in lipid peroxidation processes was recorded, which means that they may have a protective role in oxidative stress. Experimental results indicate that the essential oil of $M$. peregrinum collected from the Senta locality (No.3) exhibited the strongest inhibitory effect on lipid peroxidation. Furthermore, the present chapter on the chemistry and biological activity of four well known Lamiaceae species explicitly prove that these plants may be an important sources of pharmalogically active substances, and thus can be used in the preparation of various herbal medicine.

\section{Author details}

Biljana Kaurinovic and Mira Popovic

Department of Chemistry, Biochemistry and Environmental Protection, University of Novi Sad, Novi Sad, Republic of Serbia

\section{Acknowledgement}

This work was supported by the Ministry of Science and Environmental Protection of the Republic of Serbia (Project No. 172058) and by the Provincial Secretariat for Science and Technological Development, Autonomous Province of Vojvodina, Republic of Serbia. 


\section{References}

[1] Dargel R (1992) Lipid Peroxidation - A Common Pathogenic Mechanism? Exp. toxicol. pathol. 44: 169-181.

[2] Ursini F, Maiorino M, Sevanian A (1991) Membrane Hydroperoxides. In: Sies H, editor. Oxidative Stress: Oxidants and Antioxidants. London: Academic Press. pp. 319-336.

[3] Kagan VE (1988) Lipid Peroxidation in Biomembranes. Boca Raton: CRC Press. 1 p.

[4] Farber JL, Kyle ME, Coleman JB (1990) Mechanisms of Cell Injury by Activated Oxygen Species. Lab. invest. 62: 670-679.

[5] Halliwell B, Gutteridge JMC. (1984) Lipid Peroxidation, Oxygen Radicals, Cell Damage and Antioxidant Therapy. Lancet. 23: 1396-1397.

[6] Holchestein P, Nordenbrand K, Ernster L (1964) Evidence for the Involvement of Iron in the ADP-Activated Peroxidation of Lipids in Microsomes and Mitochondria. Biochem. biophys. res. commun. 14: 323-328.

[7] Minotti G, Aust SD (1987) The Role of Iron in the Initiation of Lipid Peroxidation. Chem. phys. lipids. 44: 191-208.

[8] Aruoma OI, Halliwell B, Laughton MJ, Quinlan J, Gutteridge JMC (1989) The Mechanism of Initiation of Lipid Peorxidation. Evidence Against a Requirement for an Iron(II)Iron(III) Complex. Biochem. j. 258: 617-620.

[9] Tang L, Zhang Y, Qian Z, Shen X (2000) The Mechanism of $\mathrm{Fe}^{2+}$-Initiated Lipid Peroxidation in Liposomes: The Dual Function of Ferrous Ions, the Roles of the PreExisting Lipid Peroxides and the Lipid Peroxyl Radical. Biochem. j. 352: 27-36.

[10] Chatterjee SN, Agarwal S (1988) Liposomes as Membrane Model for Study of Lipid Peroxidation. Free rad. biol. med. 4: 51-72.

[11] Bombardelli E, Cristoni A, Morazzobi P (1994) PHYTOSOME $^{\circledR}$ in Functional Cosmetics. Fitoterapia. 65: 397-401.

[12] http://www.pharmaxchange.info

[13] Foldvari M (2000) Non-Invasive Administration of Drugs Through the Skin. Challenges in Delivery System Design. PSTT. 3: 417-425.

[14] Immordino ML, Dosio F, Cattel L (2006) Stealth Liposomes: Review of the Basic Science, Rationale, and Clinical Applications, Existing and Potential. IJN 1(3): 297-315.

[15] Kujundžić S (2002) Biochemical Investigaion of Plant Species from the Apiaceae Family (in Serbian). Master Thesis. Novi Sad: PMF. 48 p.

[16] Laguerre M, Lecomte J, Villeneuve P (2007) Evaluation of the Ability of Antioxidants to Counteract Lipid Oxidation: Existing Methods, New Trends and Challenges. Prog. lipid res. 46: 244-282.

[17] Safer AM, Al-Nughamish AJ (1999) Hepatotoxicity Induced by the Antioxidant Food Additive Butylated Hydroxytoluene (BHT) in Rats: An Electron Microscopical Study. Histol. histopathol. 197: 391-406.

[18] Brraco U, Loliger J., Viret J (1981) Production and Use of Natural Antioxidants. JAOCS. 58: 686-690.

[19] Lagouri V, Blekas G, Tsimidou M, Kokkini S, Boskou D (1993) Composition and Antioxidant Activity of Essential Oil from Oregano Plants Grown in Greece. Z. lebensmitt.- unters. forsch. 197: 20-23. 
[20] Crowell PL, Ayoubi S, Burke YD (1996) Antitumorigenic Effects of Limopnene and Perillyl Alcohol Against Pancreatic and Breast Cancer. Adv. exp. med. biol. 401: 131-136.

[21] Carlson J, Borg AK, Unelius R, Shoshan MC, Wilking N, Ringborg U, Linder S (1996) Inhibition of Tumor Cell Growth by Monoterpenes in Vitro: Evidence of a RasIndependent Mechanism of Action. Anti-cancer drugs. 74(4): 422-429.

[22] Ruberto G, Baratta M.T, Deans SG, Dorman HJD (2000) Antioxidant and Antimicrobal Activity of Foeniculum vulgare and Crithmum maritimum Essential Oils. Planta med. 66: 687-693.

[23] Namiki M (1990) Antioxidants/Antimutagens in Food. Food sci. nutr. 29: 273-300.

[24] Rice-Evans CA, Miller NJ, Paganga G (1996) Structure-Antioxidant Activity Relationships of Flavonoids and Phenolic Acids. Free radic. biol. med. 20: 933-956.

[25] Cotelle N (2001) Role of Flavonoids in Oxidative Stress. Cur. topics med. chem. 1: 569-590.

[26] Rice-Evans CA, Miller NJ, Paganga G (1996) Antioxidant Properties of Phenolic Compounds. Trends plant sci. 2: 152-159.

[27] 1. \& 2. European Directorate for the Quality of Medicines (2002) European Pharmacopeia, 4th edition. Council of Europe. France: Strasbourg Cedex. pp. 183-184.

[28] Afanas'ev A, Dorozhko I, Brodski V, Kostyk A, Potapovich I (1989) Chelating and Free Radical Scavenging Mechanism of Inhibitory Action of Rutin and Quercetin in Lipid Peroxidation. Biochem. pharmacol. 38: 1763-1769.

[29] Fukuzawa K, Seko T, Minami K, Terao J (1993) Dynamics of Iron-Ascorbate-Induced Lipid Peroxidation in Charged and Uncharged Phospholipid Vesicles. Lipids. 28: 497-503.

[30] Buege AJ, Aust DS (1988) Methods in Enzymology. New York: Academic Press. 302 p.

[31] Janero DR (1990) Malondialdehyde and Thiobarbituric Acid-Reactivity as Diagnostic Indices of Lipid Peroxidation and Peroxidative Tissue Injury. Free rad. biol. med. 9: 515-540.

[32] Naghibi F, Mosaddegh M, Motamed MS, Ghorbani A (2005) Labiatae Family in Folk Medicine in Iran: From Ethnobotany to Pharmacology. IJPR. 2: 63-79.

[33] Hammer KA, Carson CF, Riley TV (1999) Antimicrobial Activity of Essential Oils and Other Plant Extracts. J. appl. microbiol. 86(6): 986-990.

[34] Cantino PD, Harley RM, Wagstaff SJ (1992) Genera of Labiatae: Status and Classification. In: Harley RM, Reynolds T, editors. Advances in Labiate Science. London: Royal Botanic Gardens. pp. 511-522.

[35] Kaurinović B (2008) Antioxidant Activities of Laurus nobilis L. and Melittis melissophyllum L. Extracts (in Serbian). PhD Thesis. Novi Sad: PMF. 68 p.

[36] Honda T, Rounds BV, Bore L, Finlay HJ, Favaloro FG, Suh N, Wang Y, Sporn MB, Gribble GW (2000) Synthetic Oleanane and Ursane Triterpenoids with Modified Rings A and C: A Series of Highly Active Inhibitors of Nitric Oxide Production in Mouse Macrophages. J. med. chem. 43: 4233-4246.

[37] Kuzuhara H, Nishiyama S, Minova N, Sasaki K, Omoto S (2000) Protective Effects of Soyasapogenol a on Liver Injury Mediated by Immune Response in a Concavalin AInduced Hepatitis Model. EJP. 391: 175-181.

[38] Shibata SS (2001) Chemistry and Cancer Preventing Activities of Ginseng Saponins and Some Related Triterpenoid Compounds. J. Korean med. sci. 16: 28-37.

[39] Zhang Z, Chang Q, Zhu M, Huang Y, Ho WK, Chen Z (2001) Characterization of Antioxidants Present in Hawthorn Fruits. J. nutr. biochem. 12: 144-152.

[40] Velasco-Negueruela A, Sanz J, Perez-Alonso MJ, Pala-Paul J (2004) The Volatile Components of the Aerial Parts of Melittis melissophyllum L. Bot. complutensis. 28: 133-136. 
[41] http://www.ang.kfunigraz.ac.at/ katzer/engl.html

[42] Skrzypczak-Pietraszek E, Hensel A (2000) Polysaccharides from Melittis melissophyllum L. Herb and Callus. Pharmazie. 55: 768-771.

[43] Skrzypczak, E.; Skrzypczak, L. (1993) The Tissue Culture and Chemical Analysis of Melittis melissophyllum L. Acta hort. 330: 263-267.

[44] http://www.umm.edu/altmed.html

[45] http://www.hort.purdue.edu/newcrop/med-aro.html

[46] Guarrera PM (2005) Traditional Phytotherapy in Central Italy (Marche, Abruzzo, and Latium). Fitoterapia. 76: 1-25.

[47] Maggi F, Bílek T, Lucarini D, Papa F, Sagratini G, Vittori S (2009) M. melissophyllum L. subsp. melissophyllum (Lamiaceae) from Central Italy: A New Source of a MushroomLike Flavour. Food chem. 113: 216-221.

[48] Kaurinovic B, Popovic M, Vlaisavljevic S, Raseta M (2011) Antioxidant Activities of Melittis melissophyllum L. (Lamiaceae). Molecules. 16: 3152-3167.

[49] Doba T, Burton GW, Ingold KU (1985) Antioxidant and Co-Oxidant Activity of Vitamin C. The Effects of Vitamin C, Either Alone or in the Presence of Vitamin E or a WaterSoluble Vitamin E Analogue, Upon the Peroxidation of Aqueous Multimalleral Phospholipid Liposomes. Biochim. biophys. acta. 835: 298-303.

[50] http://www.phytochemicals.info/phytochemicals/quercetin.php

[51] Acland ML, van de Waarsenburg S, Jones R (2005) Synergistic Antiproliferative Action of the Flavonols Quercetin and Kaempferol in Cultured Human Cancer Cell Lines. In vivo. 19(1): 69-76.

[52] http://www.phytochemicals.info/phytochemicals/rutin.php

[53] Decker EA (1997) Phenolics: Prooxidants or Antioxidants? Nutr. rev. 55: 396-407.

[54] Handa SS, Sharma A, Chakraborti KK (1986) Natural Products in Plants as Liver Protecting Drugs. Fitoterapia. 57: 307-310.

[55] Cholbi MR, Paya M, Alcaraz MJ (1991) Inhibitory Effect of Phenolic Compounds on $\mathrm{CCl}_{4}$-Induced Microsomal Lipid Peroxidation. Experimentia. 47: 195-198.

[56] Sousa RL, Marletta MA (1985) Inhibition of Cytochrome P-450 Activity in Rat Liver Microsomes by the Natural Occuring Flavonoid, Quercetin. Arch. biochem. biophys. 240: 345-348.

[57] Rekka E, Kourounakis PN (1991) Effect of Hydroxyethyl Rutoside and Related Compounds on Lipid Peroxidation and Free Radical Scavening Activity. Some Structural Aspects. J. pharmac. pharmacol. 43: 486-490.

[58] Larson RA (1988) The Antioxidant of Higher Plants. Phytochemistry. 27: 969-978.

[59] Cock C, Samman S (1996) Flavonoids Chemistry Metabolism, Cardioprotectioeffects and Dietary Sources. Nutrit. biochem. 7: 66-76.

[60] Stanković SM (2011) Total Phenolic Content, Flavonoid Concentration and Antioxidant Activity of Marrubium peregrinum L. Extracts. Kragujevac j. sci. 33: 63-72.

[61 Vlaisavljevic S (2007) Antioxidant Activities of Marrubium peregrinum L. Essential Oil and Extracts. Master Thesis. Novi Sad: PMF. 36 p.

[62] Nagy M, Gergel D, Grancai D, Novomesky P, Ubik K (1996) Antilipoperoxidative Activity of Some Phenolic Constituents from Marrubium peregrinum L. FarmaceutickyObzor. 65: 283-285. 
[63] Sahpaz S, Hennebelle T, Bailleul F (2002) Marruboside, a New Phenylethanoid Glycoside from Marrubium vulgare L. Nat. prod. lett. 16: 195-199.

[64] Gruenwald J, Brendler T, Jaenicke C (2000) PDRc for Herbal Medicines. NewYork: Medical Economics Co. 271 p.

[65] Salei LA, Popa DP, Lazurēvskii GV (1967) Diterpenoids from Marrubium peregrinum L. Chem. nat. comp. 2: 200-201.

[66] Hennebelle T, Sahpaz S, Skaltsounis AL, Bailleul F (2007) Phenolic Compounds and Diterpenoids from Marrubium peregrinum. Biochem. systemat. ecol. 35: 624-626.

[67] Demirci B, Baser HC, Kirimer N (2004) Composition of the Essential Oil of Marrubium bourgaei ssp. Caricum P.H. Davis. J. essent. oil res. 16: 133-134.

[68] Lazari DM, Skaltsa HD, Constantinidis T (1999) Essential Oils of Marrubium velutinum Sm. and Marrubium peregrinum L., Growing Wild in Greece. Flavour frag. j. 14: 290-292.

[69] Nagy M, Svajdlenka E (1998) Comparison of Essential Oils from Marrubium vulgare L. and M. peregrinum L. J. essent. oils res. 10: 585-587.

[70] Khanavi M, Ghasemian L, Motlagh EH, Hadjiakhoondi A, Shafiee A (2005) Chemical Composition of the Essential Oils of Marrubium parviflorum Fisch. \& C.A. Mey. and Marrubium vulgare L. from Iran. Flavour frag. j. 20: 324-326.

[71] Kaurinovic B, Vlaisavljevic S, Popovic M, Vastag Dj, Djurendic-Brenesel M (2010) Antioxidant Properties of Marrubium peregrinum L. (Lamiaceae) Essential Oil. Molecules. 15: 5943-5955.

[72] Kaurinovic B, Popovic M, Vlaisavljevic S, Zlinska J, Trivic S (2011) In Vitro Effect of Marrubium Peregrinum L. (Lamiaceae) Leaves Extracts. FEB. 20(12): 3152-3157.

[73] Čanadanović-Brunet J, Ćetković G, Đilas S, Tumbas V, Bogdanović G, Mandić A, Markov S, Cvetković D, Čanadanović V (2008) Radical Scavenging, Antibacterial, and Antiproliferative Activities of Melissa officinalis L. Extracts. J. med. food. 11: 133-143.

[74] Tosun M, Ercisli S, Sengul M, Ozer H, Polat T (2009) Antioxidant Properties and Total Phenolic Content of Eight Salvia Species from Turkey. Biol. res. 41: 175-181.

[75] Mann J (1992) Secondary Metabolism, 2nd edition. Oxford: Oxford University Press. 279 p.

[76] Jelačić ČS, Beatović VD, Prodanović SA, Tasić RS, Moravčević ŽĐ, Vujošević MA, Vučković MS (2011) Chemical Composition of the Essential Oil of Basil (Ocimum basilicum L. Lamiacea). Chem. ind. 65(4): 465-471.

[77] Grayer RI, Kite GC, Goldstone J, Bryan SE, Paton A, Putievsky E (1996) Intraspecific Taxonomy and Essential Oil Chemotypes in Sweet Basil, Ocimum basilicum. Phytochemistry. 43: 1033-1039.

[78] Marotti M, Piccaglia E, Giovanelli E (1996) Differences in Essential Oil Composition of Basil (Ocimum basilicum L.) Italian Cultivars Related to Morphological Characteristics. J. agric. food chem. 44: 3926-3929.

[79] http://www.ars-grin.gov/cgi-bin/duke/farmacy2.pl

[80] Telci I, Elmastas M, Sahin A (2009) Chemical Composition and Antioxidant Activity of Ocimum minimum Essential Oils. Chem. nat. comp. 45: 568-571.

[81] Soran ML, Cobzac-Codruta S, Varodi C, Lung I, Surducan E, Surducan V (2009) The Extraction and Chromatographic Determination of the Essentials Oils from Ocimum basilicum L. by Different Techniques. J. phys. conf. ser. 182: 012016. 
[82] Gülçin I, Elmastaş M, Aboul-Enein YH (2007) Determination of Antioxidant and Radical Scavenging Activity of Basil (Ocimum basilicum L. Family Lamiaceae) Assayed by Different Methodologies. Phytother. res. 21: 354-361.

[83] Lee SJ, Umano K, Shibamoto T, Lee KG (2005) Identification of Volatile Components in Basil (Ocimum basilicum L.) and Thyme Leaves (Thymus vulgaris L.) and Their Antioxidant Properties. Food chem. 91: 131-137.

[84] Ruberto G, Baratta MT (2000) Antioxidant Activity of Selected Essential Oil Components in Two Lipid Model Systems. Food chem. 68: 167-174.

[85] Lewinsohn E, Ziv-Raz I, Dudai N, Tadmor Y, Lastochkin E, Larkov O, Chaimovitsh D, Ravid U, Putievsky E, Pichersky E, Shoham Y (2000) Biosynthesis of Estragole and Methyl Eugenol in Sweet Basil (Ocimum basilicum L.). Developmental and Chemotypic Association of Allaphenol O-Methyltransferase Activities. Plant sci. 160: 27-35.

[86] Tucakov J (1997) Healing With Herbs (Phytotherapy) (in Serbian). Beograd: Rad. 34 p.

[87] Kootstra A (1994) Protection from UV-B-Induced DNA Damage by Flavonoids. Plant mol. biol. 26: 771-774.

[88] Robak J, Gryglewski J (1988) Flavonoids are Scavengers of Superoxide Anion. Biochem. pharmacol. 37: 837-841.

[89] Kaurinovic B, Popovic M, Vlaisavljevic S, Trivic S (2011) Antioxidant Capacity of Ocimum basilicum L. and Origanum vulgare L. Extracts. Molecules. 16: 7401-7416.

[90] Lakic N, Mimica-Dukic N, Isak J, Božin B (2010) Antioxidant Properties of Galium verum L. (Rubiaceae) Extracts. Cent. eur. j. biol. 5: 331-337.

[91] W'glarz Z, Osidska E, Geszprych A, Przybyb J (2006) Intraspecific Variability of Wild Marjoram (Origanum vulgare L.) Naturally Occurring in Poland. Rev. bras. pl. med. botucatu. 8: 23-26.

[92] Arnold N, Bellomaria B, Valentini G (2000) Composition of the Essential Oil of Different Species of Origanum in the Eastern Mediterrenean. JEOR. 12: 192-196.

[93] Duke J (1997) The Green Pharmacy, the Ultimate Compendium of Natural Remedies from the World's Foremost Authority on Healing and Herbs. New York: St. Martin's Press.

[94] Souza EL, Stamford TLM, Lima EO, Trajano VN (2007) Effectiveness of Origanum vulgare L. Essential Oil to Inhibit the Growth of Food Spoiling Yeasts. Food Control. 18: 409-413.

[95] Vekiari SA, Oreopoulou V, Tzia C, Thomopoulos CD (1993) Oregano Flavonoids as Lipid Antioxidants. J. am. oil chem. soc. 70: 483-487.

[96] Chevolleau S, Mallet JF, Ucciani E, Gamisans J, Gruber M (1992) Effects of Rosemary Extracts and Major Constituents on Lipid Oxidation and Soybean Lipoxygenase Activity. J. am. oil chem. soc. 69: 1269-1271.

[97] Kramer RE (1985) Antioxidants in Clove. J. am. oil chem. soc. 62: 111-113.

[98] Milos M, Mastelic J, Jerkovic I (2000) Chemical Composition and Antioxidant Effect of Glycosidically Bound Volatile Compounds from Oregano (Origanum vulgare L. ssp. Hirtum). Food chem. 71: 79-83.

[99] Sichel G, Corsaro C, Scalia M, Dibilio J, Bonomo R (1991) In Vitro Scavenger Activity of Some Flavonoids and Melanins Against O2. Free rad. biol. med. 11: 1-8.

[100] Rice-Evans C, Miller NJ, Paganga G (1997) Antioxidant Properties of Phenolic Compounds. Trends plant sci. 2: 152-159. 